\title{
Astronomia no ensino fundamental: um estudo de caso no interior do estado do Pará
}

Astronomy in elementary school: a case study in the interior of the state of Pará

\author{
B. M. Quaresma*; C. S. Ribeiro; R. C. Araújo; A. L. F. Novais; M. L. Chagas; L. \\ M. Gomes; F. C. L. Ferreira \\ Programa de Pós-Graduação em Ensino de Física, Universidade Federal do Sul e Sudeste do Pará, 68500-000, \\ Marabá - PA, Brasil \\ *brunoamam@yahoo.com.br \\ (Recebido em 04 de março de 2019; aceito em 18 de junho de 2019)
}

\begin{abstract}
As atuais estruturas do ensino fundamental trazem, na disciplina de ciências, conceitos importantes de Astronomia, o que proporciona um trabalho integrado à outras disciplinas, mas desconexo e difuso, como vemos na pesquisa realizada junto ao $6^{\circ}$ e $9^{\circ}$ ano do fundamental anos finais. Foi realizado uma avaliação dos materiais didáticos disponíveis, bem como da prática docente em sala de aula. Então, buscando encontrar soluções para a compreensão dos conceitos e abordagem da Astronomia, o objetivo deste trabalho foi identificar juntos aos discentes as suas análises e dificuldade quanto a esse conhecimento. A metodologia foi um questionário sobre seus conhecimentos prévios, suas dificuldades e interesses pela Astronomia. Os resultados foram satisfatórios, indicando que há uma necessidade de sincronia e continuidade ao longo das séries para que haja um maior interesse e alicerce dos conteúdos, além de uma metodologia eficiente no ensino, o que carece de materiais e espaços apropriados, assim como formação continuada dos professores e alteração curricular na inserção dos conteúdos de Astronomia no decorrer dos anos do ensino de ciências. Palavras-chave: Ciências, ensino, discente.
\end{abstract}

The current structures of elementary education bring, in the discipline of sciences, important concepts of Astronomy, which provides a work integrated to other disciplines, but disconnected and diffuse, as we see in the research conducted in the 6th and 9th year of the fundamental final years. An evaluation was made of the available didactic materials, as well as of the teaching practice in the classroom. Then, in order to find solutions for the understanding of the concepts and approach of Astronomy, the objective of this work was to identify to the students their analyzes and difficulty in this knowledge. The methodology was a questionnaire about their previous knowledge, their difficulties and interests in Astronomy. The results were satisfactory, indicating that there is a need for synchrony and continuity throughout the series so that there is a greater interest and foundation of the contents, besides an efficient teaching methodology, which lacks appropriate materials and spaces, as well as continuous training of teachers and curricular change in the insertion of Astronomy contents during the years of science teaching.

Keywords: Sciences, teaching, student.

\section{INTRODUÇÃO}

Reconhecidamente a Astronomia é uma ciência provecta e que desde os primórdios é incessantemente utilizada pela sociedade nas mais diversificadas formas. É possível certificar que as civilizações antigas utilizavam estes conhecimentos astronômicos para nortear suas atividades diárias. Por vários séculos, a compreensão da atuação do universo em nosso planeta representava muito mais do que misticismo ou crenças religiosas, mas também a continuidade e a perpetuação da nossa espécie.

As estações do ano, o sol a cada dia, criando a divisão entre o dia e a noite, o movimento das marés, possibilitaram a elaboração de calendários astronômicos que eram utilizados por muitas civilizações, evidenciando a relação da Astronomia com a vida cotidiana das populações.

Levando em consideração que a transmissão dos saberes ao longo dos tempos transcorreu de uma geração para outra, os conhecimentos astronômicos também sucederam desta maneira, mesmo que muitas das vezes de forma abstrata. Na década de 60, a Astronomia perde o caráter de disciplina específica e com a reforma educacional de 1996 passa a compor a área de Ciências 
Naturais e com a homologação da BNCC (Base Nacional Comum Curricular) em 2017 passa ser componente da área Ciências da Natureza e suas Tecnologias [4].

Para Simões (2008) [1] e Morão (1997) [2], a "Astronomia é a ciência que trata da constituição, da posição relativa e dos movimentos dos astros". Ela atrai a atenção e desperta à curiosidade das pessoas, independente de possuírem ou não conhecimentos científicos. Esse caráter investigativo que desperta a curiosidade das pessoas, remete a Astronomia como uma importante ferramenta na motivação dos alunos no estudo das disciplinas de Ciências, Física e Biologia.

$\mathrm{O}$ estudo do universo e dos astros abriu as fronteiras do mundo da ciência para os seres humanos. Ainda na pré-história, as civilizações primitivas perceberam a existência de mecanismos e ciclos específicos que se refletiam em suas atividades diárias e eram marcados pela posição das estrelas. A posição de determinados agrupamentos de estrelas ao longo do tempo parecia indicar os melhores períodos para plantio e colheita o que garantia a sobrevivência dos primeiros agricultores, dezenas de milhares de anos atrás.

A Astronomia está presente em praticamente todos os ramos do conhecimento científico. Porém, com a divisão do saber em disciplinas ministradas distintamente nas escolas, as noções astronômicas foram dissolvidas, gerando um decrescimento na sua importância para o ensino.

Esses efeitos são evidenciados, quando identificamos que as noções básicas sobre o Sistema Solar são repassadas nas aulas de geografia, o estudo das leis e dos movimentos dos planetas estão na ementa da disciplina física já no ensino médio. Com essa diluição, perde o ensino da Astronomia, perde o aluno e também perde o próprio professor, que se vê sem uma poderosa ferramenta de ensino aprendizagem.

Como relatam os autores Langhi e Nardi (2005) [3]

O docente não preparado para o ensino de Astronomia durante a sua formação promove o seu trabalho educacional com as crianças sobre um suporte instável, onde essa base pode vir das mais variadas fontes, desde a mídia sensacionalista até livros didáticos com erros conceituais, proporcionando uma propagação destas concepções alternativas (Langhi e Nardi, 2005, p.5) [3].

Buscando encontrar soluções para a compreensão dos conceitos e abordagem da Astronomia, o objetivo deste trabalho foi identificar juntos aos alunos do $6^{\circ}$ e $9^{\circ}$ ano as suas análises e dificuldades quanto a esse conhecimento, Astronomia.

\subsection{O ENSINO DE ASTRONOMIA NA E.M.E.F ANTÔNIO DE OLIVEIRA GORDO, MOJU/PA}

O ensino de Ciências, segundo os Parâmetros Curriculares Nacionais (1998) [4] deve nos mostrar a Ciência como um conhecimento que colabora para a compreensão do mundo e suas transformações, para a compreensão do homem como parte do universo e como indivíduo, é a meta que se propõe para o ensino da área na escola fundamental.

Gonzalez et al. (2004) [5] correlaciona os frutos positivos na educação com métodos que despertem no discente o encantamento pelo aprender, onde o aluno faça parte do processo de ensino e não apenas um mero expectador de sua vida acadêmica, para isso se faz necessário que o docente lance mãos de formas inovadoras para o ato de ensinar, formas que impliquem de fato um ensino motivacional, uma vez que o discente aguce sua engenhosidade o professor fatalmente colherá resultados expressivos.

A Escola Municipal de Ensino Fundamental Antônio de Oliveira Gordo dispõe da disciplina Ciências Físicas e Biológicas (C.F.B), com carga horária anual de 80 horas, para o $6^{\circ}$ ano do fundamental anos finais e em seu plano de ensino consta para o primeiro bimestre letivo a temática Astronomia particionada nos assuntos: Astros luminosos e astros iluminados, conhecendo os astros, sistema solar, o sol e os planetas dos sistema solar, movimento da Terra, eclipse da lua e eclipse do sol.

Já no $9^{\circ}$ ano, a disciplina C.F.B apresenta uma configuração de introdução ao ensino médio nas disciplinas Química e Física e possui uma carga anual de 120 horas, constando em sua ementa para o $3^{\circ}$ bimestre os assuntos relacionados à Física divididos em: Estudos dos movimentos, 
velocidade média, velocidade instantânea, movimento com velocidade variada, aceleração média e tipos de movimentos.

Percebe-se nas ementas uma ligação ao estudo de Astronomia iniciado no $6^{\circ}$ ano, contudo, verificou-se com esta pesquisa uma quebra no elo da Astronomia trabalhada no $6^{\circ}$ ano com a física ministrada no $9^{\circ}$ ano, dando a ideia de Astronomia física serem disciplinas antagônicas.

\section{MATERIAIS E MÉTODOS}

A pesquisa realizou-se na Escola Municipal de Ensino Fundamental Antônio de Oliveira Gordo, localizada na Av. das Palmeiras, Centro, Moju, Estado do Pará. Após a realização de uma visita ao local de estudo com intenção de solicitar as autorizações necessárias para o andamento da pesquisa, foi aplicado um questionário com a intenção de avaliar o conhecimento prévio dos alunos em relação ao estudo de Astronomia, contendo 4 (quatro) perguntas semiestruturadas para 30 alunos do $6^{\circ}$ ano em uma faixa etária compreendida entre 11 a 13 anos e 30 alunos do $9^{\circ}$ ano na faixa etária de 14 a 15 anos do ensino fundamental anos finais. Para a coleta de dados, aplicouse o Termo de Assentimento Livre e Esclarecimento (TCLE) com os envolvidos na pesquisa. Para corroborar foi realizado uma avaliação dos materiais didáticos disponíveis, bem como da prática docente em sala de aula.

Os dados coletados por meio dos questionários foram analisados por meio de estatística descritiva e apresentados neste artigo em forma de gráficos com a intenção de auxiliar pesquisas no ensino de Astronomia.

\section{RESULTADOS E DISCUSSÃO}

\subsection{Pesquisa com os alunos do $6^{\circ}$ ano}

Os resultados serão apresentados de 5 (cinco) questões aplicadas aos alunos do $6^{\circ}$ ano, de caráter objetivo, a saber: 1) Você estudou sobre Astronomia? 2) Você gostou de estudar Astronomia? 3) Seu professor(a) lhe incentiva a realizar alguma pesquisa sobre Astronomia? 4) O que mais chamou sua atenção ao estudar Astronomia? 5) Na sua opinião o que o professor poderia fazer para melhorar a aula?

No que tange a questão 1, pode-se observar que $97 \%$ dos alunos entrevistados estudaram o tema de Astronomia e apenas 3\% não recordam de ter estudado em algum momento na escola sobre Astronomia. Diante disso, percebe-se que a maioria dos alunos possuem conhecimento sobre o assunto supracitado.

No que se refere a questão 2, percebe-se que $53 \%$ dos alunos entrevistados relataram que gostam de estudar Astronomia e 43\% deles relataram que gostam de estudar em parte. A Figura 1 apresenta os resultados da questão que trata se alunos gostam de estudar Astronomia.

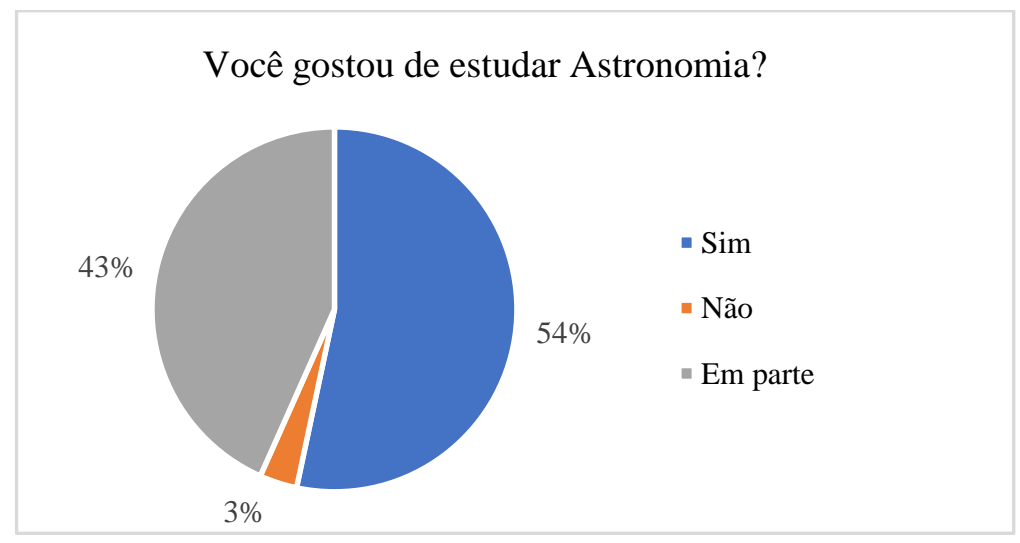

Figura 1: Apresentação os dados da questão que trata que alunos gostam de estudar Astronomia. 
Diante dos resultados obtidos, pode-se evidenciar que a maioria dos alunos que estão no $6^{\circ}$ ano já possuem conhecimentos e que gostam do tema, mesmo não tendo aulas prática para demonstração e que apenas 3\% não gostam de estudar sobre Astronomia.

$\mathrm{Na}$ questão em que faz a indagação aos alunos se são incentivados sobre pesquisa em Astronomia, 67\% dos entrevistados relataram que são incentivados pelos professores e $37 \%$ não são incentivados sobre a pesquisa em Astronomia. A Figura 2 apresenta o percentual de alunos que recebem incentivos para pesquisa sobre Astronomia.

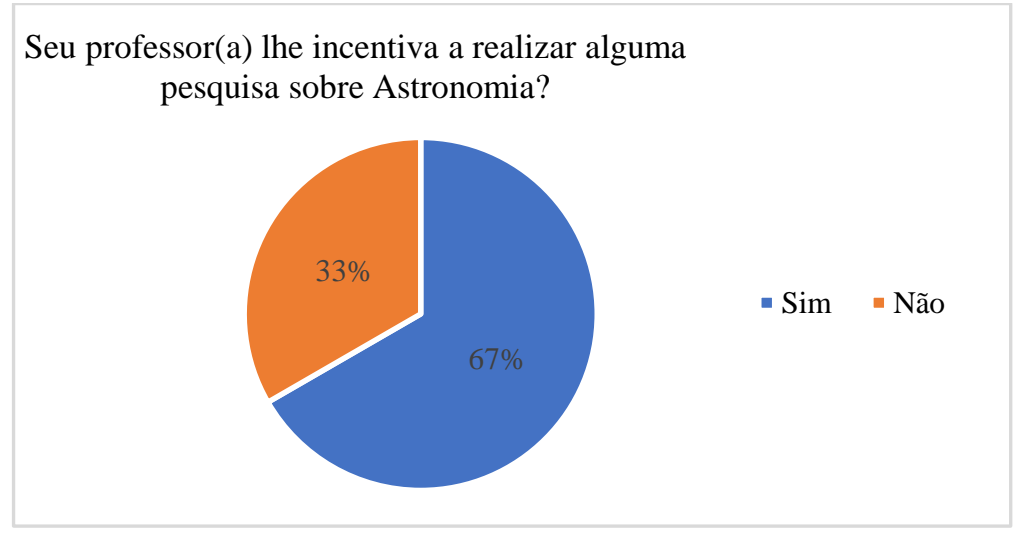

Figura 2: Percentual de alunos que recebem incentivos para pesquisa sobre Astronomia.

Diante disso, percebe-se que os alunos precisam ser incentivados, a partir do sexto ano, a pesquisar sobre Astronomia, apresentando aulas prática, videos e também momentos de interação com as universidades para ministrarem palestras sobre Astronomia. Consequentemente, a Universidade mais próxima da escola poderá apresentar ideias que desperte o interesse dos alunos por determinados temas que as vezes acham pouco relevante. A Figura 3 apresenta o tema que chama mais atenção ao estudar Astronomia pelos alunos.

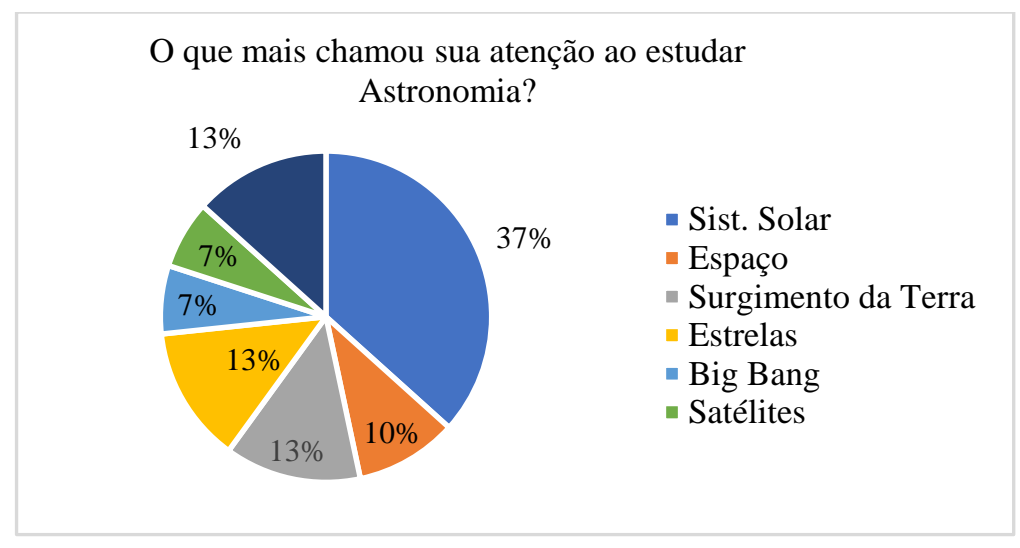

Figura 3: Percentual dos alunos interessados no tema de Astronomia.

Na Figura 3 fornece um resultado diversificado, tais como 37\% tem mais interesse no tema sistema solar, $13 \%$ no surgimento da terra, $10 \%$ sobre o tema espaço, $7 \%$ para cada Big Bang e satélites e sem resposta foram $13 \%$ dos entrevistados. Diante disso, percebe-se que $87 \%$ dos entrevistados tiveram uma motivação no tema de Astronomia e acredita-se que a melhor contribuição seria incentivar os alunos a participarem de eventos de Astronomia [6] e de olimpíadas de Astronomia. A Figura 4 apresenta o percentual de sugestões para melhoras a aula. 


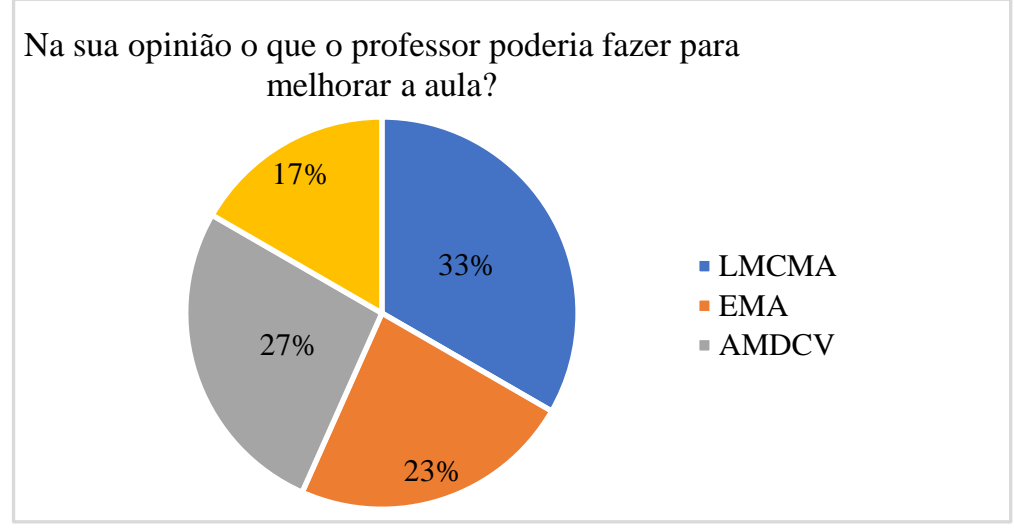

Figura 4: Percentual de sugestões para melhoras a aula.

Na Figura 4 mostra um resultado ainda mais diversificado, com quatro das respostas nos chamaram mais atenção, foram elas: Liberar mais cedo ou menos aulas (LMCMA) com um total de 33\% dos entrevistados; explicar melhor os assuntos (EMA) com 23\% dos alunos e tornar as aulas mais divertidas com vídeos (AMDCV) obtendo um resultado de $27 \%$ e sem repostas foi $17 \%$.

Fazendo uma análise dos resultados obtidos nas Figuras 1 a 4 , observou-se uma certa contrariedade nas respostas dadas pelos alunos, principalmente nas Figuras 3 e 4.

No principio das entrevistas com os alunos, percebeu-se que $93 \%$ já tinha estudado sobre o tema de Astronomia e 67\% dos entrevistados foram estimulados pelo professor, fato este representado na Figura 3 que indica uma variedade de temas abordados e que são de interesse dos alunos, dentre eles, destaca-se "O Sistema Solar" com 37\% dos entrevistados. Porém, um resultado preocupante indica que cerca de 33\% responderam que para melhor a aula, o professor deveria lecionar menos aulas ou liberar os alunos mais cedo.

Pode-se perceber um reflexo das metodologias utilizadas em sala, pois indica que $27 \%$ gostariam de ter uma aula mais atrativa e dinâmica com a utilização de computadores, datashow, vídeos e até mesmo com o lúdico se fazendo presente nas aulas.

\subsection{Pesquisa com os alunos do $9^{\circ}$ ano}

Os resultados apresentados serão de 5 (cinco) questões aplicadas aos alunos do $9^{\circ}$ ano, de caráter objetivo, a saber: 1) Você estudou sobre Astronomia? 2) Você gostou de estudar Astronomia? 3) Seu professor(a) lhe incentiva a realizar alguma pesquisa sobre Astronomia? 4) O que mais chamou sua atenção ao estudar Astronomia? 5) Na sua opinião o que o professor poderia fazer para melhorar a aula?

Para fazer uma análise mais próxima possível da realidade do ensino de Astronomia em séries/anos diferentes, repetiu-se as mesmas cinco perguntas aplicadas aos alunos do $6^{\circ}$ ano.

No entanto, percebeu-se que $63 \%$ dos alunos entrevistados responderam que não estudaram Astronomia e $37 \%$ não estudaram Astronomia. No que tange a pergunta 2, as respostas apresentaram um resultado preocupante apontando que $43 \%$ dos alunos entrevistados não gostaram de estudar Astronomia, 30\% gostaram em parte, $20 \%$ apenas gostaram da disciplina e que $7 \%$ não responderam.

No que concerne a pergunta sobre o seu professor(a) lhe incentiva a realizar alguma pesquisa sobre Astronomia, observou-se que $90 \%$ dos entrevistados afirmaram que não são incentivados pelo professor a realização de pesquisas e quanto a pergunta que trata quando sobre o que mais chamou sua atenção ao estudar Astronomia, notou-se que o total de alunos entrevistados $34 \%$ tiveram sua atenção para o sistema solar, apenas 3\% para o espaço, 23\% não tiveram interesse em nenhum assunto abordado, 7\% foram atraídos pelas vidas em outros planetas (VEOP) e 33\% sem resposta (SR). Quando questionados sobre o que o professor poderia fazer para melhorar a aula, observou-se que $44 \%$ dos entrevistados disseram que para melhorar a aula, o professor deveria explicar melhor o conteúdo, $10 \%$ gostariam que tivessem aulas mais divertidas por 
exemplo com vídeos (AMDCV), 3\% indicaram que o uso do celular poderia ter um resultado melhor, 3\% indicaram que para melhorar o professor deveria ajudar os alunos que têm mais dificuldades de aprendizagem no conteúdo (AACMD) e $40 \%$ não responderam.

Fazendo uma análise da pesquisa realizada com os alunos do $9^{\circ}$ ano do ensino fundamental, percebe-se que os alunos não conseguem identificar que a Astronomia está presente nos conteúdos quando $63 \%$ informam não terem estudado a disciplina.

Portanto, percebeu-se que 73\% não gostam ou gostam em parte de estudar sobre Astronomia, um número elevado que talvez possa ser explicado que $90 \%$ dos alunos não são estimulados pelo professor a realizar pesquisa e portanto talvez pela falta de incentivo por parte dos professores e que possa ser resolvido com a interação entre universidade e escola.

\section{CONCLUSÃO}

A pesquisa realizada na E.M.E.F Antônio de Oliveira Gordo, nos remete a uma reflexão em nossa prática docente sobre o modo de pesquisar, ensinar e incentivar nossos alunos. Os dados aqui apresentados nos mostram claramente a falta de uma compreensão da importância do estudo astronômico como uma ferramenta poderosa no processo de ensino e aprendizagem.

Constatou-se que, mesmo com todo o aparato tecnológico que está a sua disposição, muitos alunos não conseguem identificar, o que é e qual a importância de Astronomia na vida da sociedade, chegando ao inimaginável disparate que alguns alunos recomendaram que para melhorar a temática Astronomia, bastava o docente lecionar uma quantidade menor de aulas ou liberá-los mais cedo, isso pode ser reflexo da metodologia nada atrativa utilizada, fazendo com que os discentes desenvolvam um desinteresse coletivo.

Atestou-se assustadoramente que $44 \%$ dos entrevistados identificaram no docente a falta de uma forma de ensino mais acessível, por isso a importância de dispormos de professores cada vez mais preparados e atualizados em constantes formações, é notória que os discentes necessitam serem estimulados para o estudo de astronomia, somando os $44 \%$ que indicaram que o docente deve explicar melhor com os $40 \%$ que não responderam, por talvez não conseguirem identificarem a necessidade do entendimento acerca da temática, chegamos ao espantoso valor de $84 \%$ que ratifica uma mudança imediata na forma metodológica a ser utilizada pelos docentes.

Alunos desestimulados, professores com falta ou não uso de equipamentos tecnológicos, falta de incentivo à pesquisa estão dentre as problemáticas identificadas no ensino de Astronomia na Escola pesquisada.

\section{AGRADECIMENTOS}

Os autores agradecem à CAPES, ao CNPq, ao MNPEF e à Propit/Unifesspa pelo apoio nas pesquisas.

\section{REFERÊNCIAS BIBLIOGRÁFICAS}

1. Simões CC. Elementos de astronomia nos livros didáticos de física [dissertação]. Belo Horizonte (MG): Pontifícia Universidade Católica de Minas Gerais; 2008. 144p.

2. Mourão RRF. Da terra às galáxias: uma introdução à astrofísica. Rio de Janeiro: Editora Vozes; 1997. 403p.

3. Langhi R, Nardi R. Dificuldades Interpretadas nos Discursos de Professores dos Anos Iniciais do Ensino Fundamental em Relação ao Ensino da Astronomia. Rev Latino-Americana Ed Astron. 2005;(2):75-92.

4. Brasil. Parâmetros Curriculares Nacionais: terceiro e quarto ciclos do ensino fundamental: introdução aos parâmetros curriculares nacionais. Brasília: MEC/SEF. 1998. 174 p. Disponível em 〈http://portal.mec.gov.br/seb/arquivos/pdf/introducao.pdf〉. Acessado em 20 de novembro de 2018.

5. Gonzalez EAM, Nader RV, Mello AB, Pinto SS, Pereira DNE, Souza E, Campos JSA. Astronomia como ferramenta motivadora no ensino das ciências. In: Congresso Brasileiro de Extensão Universitária. 2004(2):1-7. Belo Horizonte: Universidade Federal de Minas Gerais. Disponível em: $<$ http://www.ufmg.br/congrext/Educa/Educa5.pdf >. Acessado em 15 setembro 2018.

6. Nogueira S, Canalle JBG. Astronomia: ensino fundamental e médio. Brasília: MEC, SEB; MCT; AEB, 2009;(11) 232 p. (Coleção Explorando o ensino). Disponível em<http://portal.mec.gov.br/index.php?option=com_docman\&view=download\&alias=4232- 
colecaoexplorandooensino-vol11\&category_slug=marco-2010-pdf\&Itemid=30192>. Acessado em 15 de setembro de 2018. 